\title{
A crescente presença da epistemologia de Ludwik Fleck na pesquisa em educação em ciências no Brasil ${ }^{1}$
}

Leonir Lorenzetti leonirlorenzetti22@gmail.com 0000-0001-8327-9147 Universidade Federal do Paraná Curitiba, Paraná

Cristiane Muenchen crismuenchen@yahoo.com.br 0000-0003-3144-0933 Universidade Federal de Santa Maria,

Departamento de Física

lône Ines Pinsson Slongo ione.slongo@uffs.edu.br 0000-0002-2103-0896 Universidade Federal da Fronteira Sul

\section{RESUMO}

O estudo investigou a recepção da epistemologia de Ludwik Fleck pela pesquisa em Educação em Ciências no Brasil. Foram analisadas 89 dissertações e teses produzidas no período de 1995 a 2015, sendo que 37 trabalhos discutem a Educação em Ciências. Os dados apontam que na década de 1990 surgiram os primeiros estudos e que há uma concentração de trabalhos na Universidade Federal de Santa Catarina, especialmente na área da Educação em Ciências. Uma análise em profundidade, a partir de 6 eixos, foi realizada em 34 trabalhos que discutem a Educação em Ciências. O estudo identificou que o maior volume está concentrado nos eixos "formação de professores" e "emergência de um fato científico". Destaca-se a significativa contribuição das categorias epistemológicas "estilo de pensamento", "coletivo de pensamento" e "circulação intra e intercoletiva de ideias" no processo de produção do conhecimento.

PALAVRAS-CHAVE: Ludwik Fleck. Produção acadêmica. Educação em ciências. Estado do conhecimento. Categorias Fleckianas. 


\section{INTRODUÇÃO E CONTEXTUALIZAÇÃO}

Este artigo relata estudo que é parte de um projeto mais amplo e interinstitucional e que tem como objetivo realizar balanços permanentes sobre a produção acadêmica em Educação em Ciências desenvolvida no Brasil, em diferentes recortes temáticos e temporais.

Estudos desta natureza, que realizam balanços críticos sobre a produção científica, são de grande relevância para a área, dada sua contribuição na sistematização do já produzido, como também, na identificação de lacunas e novas demandas, contribuindo para orientar o desenvolvimento da pesquisa na área. Soares e Maciel $(2000$, p. 6) recomendam que esses estudos sejam ininterruptos, dada sua contribuição:

[...] a identificação, caracterização e análise do 'estado do conhecimento' sobre determinado tema é fundamental no movimento ininterrupto da ciência ao longo do tempo. Assim, da mesma forma que a ciência se vai construindo ao longo do tempo, privilegiando ora um aspecto ora outro, ora uma metodologia ora outra, ora um referencial teórico ora outro, também a análise, em pesquisas de 'estado do conhecimento' produzidas ao longo do tempo, deve ir sendo paralelamente construída, identificando e explicitando os caminhos da ciência, para que se revele o processo de construção do conhecimento sobre determinado tema, para que se possa tentar a integração de resultados e, também, identificar duplicações, contradições e, sobretudo, lacunas, isto é, aspectos não estudados ou ainda precariamente estudados e metodologias de pesquisa pouco exploradas.

Outra contribuição importante dos estudos bibliográficos de natureza inventariante refere-se à ampliação da divulgação dos dados produzidos (SOARES; MACIEL, 2000; FERREIRA, 2002; ROMANOWSKI; ENS, 2006; GAMBOA, 2008). Sempre que uma área do conhecimento registra desenvolvimento expressivo, o que inclui o aumento quantitativo de estudos, faz-se necessário o ordenamento da produção, de modo a realizar "sínteses integrativas" (ANDRÉ, 2002) das diversas pesquisas e, assim, oferecer maior sustentação aos estudos futuros.

No Brasil, a socialização do conhecimento produzido na forma de teses e dissertações ainda é incipiente, principalmente se considerada a crescente expansão da pós-graduação stricto sensu ocorrida nas últimas décadas. Este fator tem contribuído para o crescimento quantitativo de estudos, como também, da diversidade de enfoques assumidos pela pesquisa em Educação em Ciências. Por sua vez, os mecanismos de divulgação destas pesquisas seguem os padrões inaugurados há décadas.

A etapa inicial da pesquisa ora relatada resultou em um primeiro artigo (LORENZETTI; MUENCHEN; SLONGO, 2013) que analisou a presença da matriz epistemológica de Fleck (1986; 2010) na pesquisa em Educação em Ciências desenvolvida no Brasil, no período de 1995 a 2010. Cinco anos após, apresentamos os resultados de uma segunda etapa deste estudo, que incorpora novos dados ao período anteriormente analisado, ampliando o recorte temporal para 2015. Assim, ao analisar a produção deste período mais recente, buscamos estabelecer uma espécie de continuum com a etapa anterior, analisando o conjunto de dados de forma articulada. Portanto, os resultados anunciados neste artigo referem-se ao período de 1995 a 2015, cobrindo duas décadas de produção acadêmica em teses 
e dissertações em Educação em Ciências, subsidiadas pela teoria da ciência de Ludwik Fleck $(1986 ; 2010)$ e desenvolvidas em programas nacionais de pósgraduação. Buscou-se explicitar o modo como a grande área Educação em Ciências vem dialogando com este referencial epistemológico.

Os dados produzidos ao longo das duas décadas permitem inferir que há, no Brasil, atualmente, um coletivo de pesquisadores em Educação em Ciências que compartilham deste referencial epistemológico, o qual tem potencializado pesquisas a pesquisa na área.

\section{NOTAS SOBRE LUDWIK FLECK}

Ludwik Fleck (1896-1961), médico e filósofo de origem judia, nasceu em 1896, em Lwów, na Polônia, atual região da Ucrânia, e morreu em Israel, em 1961. Dedicou-se à medicina, atuando como clínico e pesquisador nas áreas de bacteriologia, microbiologia e imunologia, tendo sido um dos precursores desta última. Paralelamente, estudou sociologia, filosofia e história da ciência (SCHÄFER; SCHNELLE, 1986), acumulando importante produção no campo da epistemologia (DA ROS, 2000; DELIZOICOV et al., 2002; PFUETZENREITER, 2003).

Influenciado pela Escola Polonesa de Filosofia da Medicina e contrapondo-se ao empirismo lógico do Círculo de Viena (LÖWY, 2004), Fleck desenvolveu sua reflexão epistemológica, partindo da premissa de que o conhecimento é fruto de processos sócio-históricos, efetuado por coletivos de pensamento em interação sociocultural. Considerou que o conhecimento produzido por esses coletivos está em conformidade com uma estrutura de pensamento predominante na sociedade em cada momento histórico. Desse modo, Fleck $(1986 ; 2010)$ propôs as categorias epistemológicas estilo de pensamento, coletivo de pensamento, circulação intercoletiva e intracoletiva de ideias, com as quais analisou a gênese e a difusão de conhecimentos e práticas produzidas por esses coletivos.

Ao descrever a trajetória histórica do conceito de sífilis (FLECK, 1986; 2010), definiu coletivo de pensamento como sendo a unidade social da comunidade de cientistas de um campo determinado do saber e estilo de pensamento como sendo o conjunto de pressuposições sobre as quais o coletivo de pensamento constrói seu edifício teórico. Argumentou que o saber nunca é possível em si mesmo, mas sob determinadas condições e suposições sobre o objeto as quais não podem tornar-se compreensíveis a priori, mas como produto histórico e sociológico da atuação de um coletivo de pensamento. Desse modo, caracterizou estilo de pensamento como o conjunto de conhecimentos e práticas, concepções, tradições e normas compartilhadas pelos membros do coletivo de pensamento, cabendoIhe o papel de direcionador do modo de pensar e de agir do coletivo de pensamento, possibilitando-lhe uma maneira própria de ver e interagir com o objeto do conhecimento. Por sua vez, sendo o coletivo de pensamento o portador comunitário do estilo de pensamento, cabe-lhe determinar, em cada época, os problemas de pesquisa pertinentes e relevantes a serem solucionados (FLECK, 1986; 2010).

$\mathrm{Na}$ estrutura geral do coletivo de pensamento, Fleck (1986; 2010) distinguiu os círculos esotérico e exotérico. Definiu que o círculo esotérico é formado pelos especialistas de uma área do conhecimento e o círculo exotérico, pelos leigos e 
leigos formados. As pessoas podem pertencer a vários coletivos simultaneamente, atuando como veículos na transmissão de ideias entre eles.

A presença de um círculo esotérico, formado por especialistas de uma determinada área do conhecimento, caracteriza a identidade primeira do coletivo de pensamento, por ser este o portador do estilo de pensamento. É a partir desse núcleo de conhecimentos e de práticas compartilhadas que se formam os círculos exotéricos, quando passam a interagir, por meio de múltiplas alternativas, com o círculo esotérico. Entre os círculos esotérico e exotérico estabelecem-se relações dinâmicas que contribuem para a ampliação da área de conhecimento, através da circulação intracoletiva e intercoletiva de conhecimentos e práticas.

A circulação intracoletiva ocorre no interior do coletivo de pensamento, assegurando a extensão do estilo de pensamento, bem como o compartilhamento dos conhecimentos e práticas relativas ao estilo de pensamento vigente, de modo a formar os novos membros do grupo (FLECK, 1986; 2010). Por sua vez, a circulação intercoletiva de ideias ocorre entre dois ou mais coletivos de pensamento, contribuindo, de modo significativo, com a transformação do estilo de pensamento, pois "[...] qualquer tráfego intercoletivo de pensamento traz consigo um deslocamento ou uma alteração dos valores de pensamento" (FLECK, 2010, p. 161).

O autor considera, ainda, que a relação cognoscitiva entre sujeito e objeto a conhecer é mediatizada por um terceiro fator, o estado do conhecimento, que pressupõe as relações históricas, sociais e culturais. Assim sendo, as relações históricas presentes em um determinado estilo de pensamento indicam uma interrelação entre o conhecido e o que se quer conhecer. Logo, o processo de produção de conhecimento deve levar em consideração três elementos: o sujeito, o objeto e o estilo de pensamento compartilhado pelo coletivo de pensamento.

Na reconstrução histórica do conceito de sífilis, Fleck (1986; 2010) observou uma dinâmica que se repete na "marcha" do pensamento, fazendo com que o modo de ver, pensar e agir, ao mesmo tempo em que resiste, sofre transformações. A essa dinâmica denominou de instauração, extensão e transformação dos estilos de pensamento. Argumentou que as teorias científicas vivem, primeiro, uma fase clássica, quando todas as ideias estão em conformidade com o pensamento vigente ou com a teoria dominante. Nessa fase, o estilo de pensamento acha-se devidamente instaurado, e o esforço do coletivo de pensamento é no sentido de desenvolver o pensamento dominante, fase denominada por Fleck $(1986 ; 2010)$ de extensão do estilo de pensamento. Nesse momento, verifica-se uma ampliação do rol de problemas a investigar. Contudo, o autor aponta que, apesar da tendência à persistência, há um momento em que surgem as "complicações", as exceções ou os problemas que o estilo de pensamento não consegue resolver. Assim, instala-se um período de instabilidade e controvérsias, intensificando o debate intra e intercoletivos de pensamento. Significativas mudanças marcam esse período, as quais determinam o que Fleck (1986; 2010) denomina de transformação do estilo de pensamento e que culmina com a emergência de um novo modo de pensar e agir, isto é, um novo estilo de pensamento.

Em síntese, Ludwik Fleck é um referencial epistemológico importante e se apresenta como base de outros estudos na área da Educação em Ciências, o que 
indica a atualidade de seu pensamento epistemológico, introduzindo parâmetros de análise sobre o processo de produção e disseminação do conhecimento, estabelecendo e caracterizando as categorias que balizam sua epistemologia, com destaque para estilo de pensamento, coletivo de pensamento, circulação intercoletiva e intracoletiva de ideias, instauração, extensão e transformação do estilo de pensamento. Essas categorias epistemológicas vêm sendo utilizadas de modo recorrente e crescente no país, de forma significativa pela pesquisa em Educação em Ciências (DELIZOICOV et al., 2002; SLONGO, 2004; PARREIRAS, 2006; LORENZETTI, 2008; MUENCHEN, 2010; EMMEL, 2011; MARQUES, 2012; MILARÉ, 2013).

Este artigo apresenta, inicialmente, um panorama das pesquisas que utilizam o aporte epistemológico de Fleck, com destaque para a produção em Educação em Ciências, procurando explicitar em que momento ele se estabeleceu como referencial para a pesquisa na área, os objetos, programas e pesquisadores que buscaram esse diálogo epistemológico, a justificativa apontada para a utilização dessa epistemologia e as contribuições que a abordagem trouxe à pesquisa na área, segundo seus autores.

\section{PROCEDIMENTOS METODOLÓGICOS E PANORAMA INICIAL}

O estudo relatado configurou-se como pesquisa bibliográfica, do tipo "estado do conhecimento" (FERREIRA, 2002), e teve o objetivo de analisar a presença e recepção da epistemologia de Ludwik Fleck $(1986 ; 2010)$ na pesquisa em Educação em Ciências realizada no Brasil. Desta forma, foram analisadas dissertações e teses desenvolvidas em programas nacionais de pós-graduação, no período de 1995 a 2015, e que tiveram como horizonte de análise e interpretação a epistemologia de Fleck. O recorte temporal apresenta uma justificativa história, uma vez que a defesa da primeira dissertação identificada nas bases de dados utilizadas neste estudo data de 1995.

Os dados foram coletados no primeiro semestre de 2011 e 2016. Foram selecionadas teses e dissertações disponíveis no banco de teses da Coordenação de Aperfeiçoamento de Pessoal de Nível Superior (CAPES), no sítio http://www.capes.gov.br/servicos/banco-de-teses e na Biblioteca Digital Brasileira de Teses e Dissertações através do endereço http://bdtd.ibict.br/vufind/ utilizando as seguintes expressões de busca: "Ludwik Fleck", "Fleck" e "Estilo de Pensamento".

Desta forma, a amostra foi constituída por 89 trabalhos que utilizam a epistemologia de Fleck como referencial teórico. Na sequência, uma leitura cuidadosa do resumo de cada dissertação e tese foi realizada, objetivando verificar a pertinência e a vinculação do trabalho com o presente estudo.

Em uma primeira aproximação, as pesquisas mapeadas geraram tabelas que identificaram o volume de trabalhos desenvolvidos no período e sua concentração por áreas do conhecimento, instituições de educação superior, programas de pósgraduação onde foram gerados e respectivos orientadores.

Pelo levantamento realizado, foi possível identificar que a epistemologia de Fleck orientou os primeiros estudos em meados da década de 1990, tendo, até 
2015, subsidiado o desenvolvimento de 89 estudos, sendo 49 dissertações desenvolvidas em mestrados acadêmicos (MA), 2 dissertações oriundas de mestrados profissionais (MP) 38 teses (T) produzidas em programas de doutorado, identificando-se um predomínio de dissertações em relação às teses. Considerando o objetivo deste trabalho, de analisar a produção acadêmica que utiliza Fleck como referencial teórico, analisamos os trabalhos que tiveram como foco a Educação em Ciências. Os dados estão no Tabela 1:

Tabela 1 - Número de trabalhos mapeados

\begin{tabular}{ccccccccc}
\hline \multirow{2}{*}{ Período } & \multicolumn{3}{c}{ Áreas Diversas } & \multicolumn{4}{c}{ Educação em Ciências } \\
\cline { 2 - 9 } & MA & MF & D & Total & MA & MF & D & Total \\
\hline 1ㅇ: 1995 a 2000 & 4 & - & 2 & 6 & 2 & - & - & 2 \\
2o: 2001 a 2005 & 8 & - & 10 & 18 & - & - & 4 & 4 \\
3o: 2006 a 2010 & 17 & - & 7 & 24 & 3 & - & 4 & 7 \\
4o: 2011 a 2015 & 20 & 2 & 19 & 41 & 9 & 1 & 14 & 24 \\
Total & 49 & 2 & 38 & 89 & 14 & 1 & 22 & 37 \\
\hline
\end{tabular}

(Fonte: Os autores (2016))

Observa-se que a presença de estudos fleckianos ao longo do período é regular, com tendência ascendente. Há destaque para o volume produzido nos últimos 5 anos, superando a produção dos 15 anos iniciais.

A partir da leitura dos resumos, foi possível identificar a área do conhecimento desses trabalhos, evidenciando que a área de Ciências Humanas comparece com 32, a área Multidisciplinar com 31 trabalhos, seguindo com a área de Ciências da Saúde com 25 e a área de Engenharia com um trabalho.

A grande área de Ciências Humanas envolve os programas de Pós-Graduação em Educação, Filosofia, História, Psicologia, Sociologia Política. A área Multidisciplinar aglutina Programas ligados ao Ensino, com destaque para os programas de Educação Científica e Tecnológica, Ensino de Ciências e Matemática, Educação em Ciências, Ensino de Ciências, Ensino de Ciências e Tecnologia, entre outros. Já na área de Ciências da Saúde estão os Programas de Saúde, Saúde Coletiva, Saúde Pública, Enfermagem, Educação Física, entre outros. O Programa de Engenharia Ambiental compõe a Área das Engenharias. A Tabela 2 identifica os programas em que as 89 pesquisas foram desenvolvidas.

Tabela 2 - Número de trabalhos por programa e Instituição de Educação Superior

\begin{tabular}{c|c|c} 
Programa & Instituição de Educação Superior & Número \\
\hline Educação & $\begin{array}{c}\text { UFSC, UFPR, UNB, UNIJUI, UFSCar, UNIPLAC, } \\
\text { UNESC }\end{array}$ & $\mathbf{2 0}$ \\
\hline $\begin{array}{c}\text { Educação Científica e } \\
\text { Tecnológica }\end{array}$ & UFSC & $\mathbf{1 6}$ \\
\hline Saúde Coletiva & UERJ. UFSC, UFRJ, UNICAMP, FIOCRUZ & 13 \\
\hline História & UFRN, UFMG & $\mathbf{5}$ \\
\hline Filosofia & UERJ, UFSC, USP, UEL & $\mathbf{4}$ \\
\hline Saúde & UNIVALI & $\mathbf{4}$ \\
\hline $\begin{array}{c}\text { Educação em Ciências e } \\
\text { Matemáticas }\end{array}$ & UFPA & $\mathbf{3}$
\end{tabular}




\begin{tabular}{c|c|c} 
Educação Física & UFSC & $\mathbf{2}$ \\
\hline Enfermagem & UFSC & $\mathbf{2}$ \\
\hline Saúde Pública & UFSC, FIOCRUZ & $\mathbf{2}$ \\
\hline Educação nas Ciências & UNIJUI & $\mathbf{2}$ \\
\hline $\begin{array}{c}\text { História das Ciências e } \\
\text { Saúde }\end{array}$ & FIOCRUZ & $\mathbf{2}$ \\
\hline Outros & $\begin{array}{c}\text { UFSM-FURG-UFRGS, UFMG, UNIFESP, } \\
\text { UFRGS, UNESP, UFSC, USP, UEL, UTFPR, } \\
\text { UFBA, FIOCRUZ, UFSC, UNIVALI, UNIPLI. }\end{array}$ & $\mathbf{1 4}$ \\
\hline Total & & $\mathbf{8 9}$
\end{tabular}

(Fonte: Os autores (2016))

No levantamento realizado no período de 1995 a 2010, Lorenzetti, Muenchen e Slongo (2013), constataram o predomínio de pesquisas voltadas para a área da Saúde. Já no recorte temporal de 2011 a 2015, identificamos a ampliação significativa de trabalhos na área de Ciências Humanas e Multidisciplinar, com predomínio de estudos na área da Educação em Ciências. Porém, quando analisamos a especificidade das temáticas privilegiadas pelos trabalhos identificamos 43 trabalhos envolvendo a Educação e o Ensino, 40 trabalhos na área da Saúde e 6 na Filosofia. Isso se justifica pelo fato de trabalhos da área da Saúde terem sido desenvolvidos em outros programas. Esse dado exemplifica muito bem a circulação intercoletiva de ideias no processo de produção do conhecimento, conforme argumentou Fleck (1986; 2010). Exemplificam essa importante dinâmica, as teses de Da Ros (2000), Cutolo (2001) e Pfuetzenreiter (2003), as quais, mesmo focando em objetos específicos da área de Saúde, foram geradas no Programa de Pós-Graduação em Educação da Universidade Federal de Santa Catarina (UFSC).

Levantamento realizado por Lorenzetti (2008) indica a existência de centros de estudos no Brasil que utilizam Fleck como referência, mostrando que a citação de sua obra em pesquisas nacionais apresenta uma trajetória e uma aplicação em diferentes contextos. Esses centros estão localizados na UFSC, envolvendo os programas de Educação, Enfermagem, Saúde Pública, Filosofia, Sociologia Política e Educação Científica e Tecnológica. No estado do Rio de Janeiro, a produção envolvendo a epistemologia de Fleck está concentrada no Programa de Saúde Coletiva da Fundação Oswaldo Cruz (FIOCRUZ) e nos Programas de Saúde Coletiva e Filosofia da Universidade do Estado do Rio de Janeiro (UERJ). Já na Universidade Federal de Minas (UFMG), a epistemologia de Fleck foi utilizada no Programa de História.

Neste estudo, constata-se que a epistemologia de Fleck está sendo utilizada em 25 Instituições de Educação Superior distintas: UFSC ( $n=40)$, UERJ ( $n=7)$, UFMG $(n=5)$, UNIVALI $(n=5)$, FIOCRUZ $(n=4)$, UFPA $(n=3)$ e UEL, UFPR, UFRN, UnB, UNIPLAC, USP, todas com 2 trabalhos cada e 13 instituições contribuem com um trabalho cada, o que demonstra a disseminação da epistemologia de Fleck na comunidade acadêmica, conforme Tabela 2.

Com relação aos orientadores das dissertações e teses, os dados indicam a liderança de Demétrio Delizoicov (UFSC), que orientou 11 estudos; Kenneth Rochel de Camargo Jr. (FIOCRUZ), sete estudos; Marco Aurélio da Ros (UFSC) com seis; 
Carlos Alberto Marques (UFSC), Edel Ern (UFSC) e Luiz Roberto Agea Cutolo (UNIVALI), com quatro estudos cada; Maria Helena da Silva Carneiro (UnB), Mauro Lúcio Leitão Condé (UFMG) com três cada; Arden Zylbersztajn (UFSC), Araci Asinelli da Luz (UFPR), José Andre Peres Angotti (UFSC), Lucia Ceccatto de Lima (UNIPLAC), Maria Cristina Pansera-de-Araujo (UNIJUÍ), Maria de Fátima Vilhena da Silva (UFPA), Nadir Ferrari (UFSC) e Walter Antônio Bazzo (UFSC), com dois estudos cada. Com apenas uma orientação localizamos mais 18 orientadores distintos. Esse dado, ao mesmo tempo em que parece sugerir certa dispersão, também poderá traduzir uma importante fase de desenvolvimento de uma comunidade nacional de investigadores, que tem buscado na epistemologia de Fleck um horizonte de análise e interpretação dos fatos científicos que estudam.

Um dado que parece justificar esta inferência, é o fato de doutorandos que utilizaram Fleck em suas teses, quando passam a orientar pesquisas em programas de pós-graduação, seguem utilizando essa mesma matriz epistemológica. Como exemplo, podemos citar Marcos Aurélio da Ros, Luiz Roberto Agea Cutolo, Lucia Ceccato de Lima e Cristiane Muenchen, que utilizaram fortemente as categorias fleckianas em suas teses e as utilizam agora com seus orientandos, em estudos aqui analisados.

Queirós e Nardi (2008) apresentam um panorama da produção acadêmica que utiliza a epistemologia de Fleck como referencial teórico e que foi publicada em periódicos nacionais da área de Educação em Ciências e nas atas do Encontro Nacional de Pesquisa em Educação em Ciências, realizado no período de 2002 a 2007. Com esse foco, esses autores localizaram 13 artigos e apontaram o predomínio de objetos vinculados à área de Saúde e Ciências Biológicas. Além disso, classificaram esses estudos em quatro grandes categorias: 1) História de Fatos Científicos; 2) Concepção de professores acerca da natureza da ciência; 3) Ensino de Saúde; 4) Análises de pesquisas em Ensino de Ciências no Brasil.

De outro vértice, o estudo de Lorenzetti (2008) localizou 20 pesquisas, envolvendo dissertações e teses desenvolvidas em programas de pós-graduação, no período de 1995 a 2006. Essa produção acadêmica, que se apoia nas ideias epistemológicas de Fleck, foi categorizada pelo autor em cinco eixos: 1) Formação de professores; 2) Estudos sobre o currículo; 3) Análise sobre a emergência de um fato; 4) Relação de Fleck com outros autores; 5) Análise de produção acadêmica.

Após esse levantamento e análise inicial das 89 teses e dissertações que utilizaram o aporte epistemológico de Fleck $(1986 ; 2010)$, um estudo específico foi realizado envolvendo 34 das 89 pesquisas, cujas problemáticas investigadas pertencem à grande área de Educação em Ciências. Vale destacar que três documentos não foram analisados por não estarem disponíveis na ocasião em que o levantamento foi realizado.

Utilizando a metodologia da Análise Textual Discursiva (MORAES; GALIAZZI, 2013), focando, principalmente, no resumo, introdução, metodologia, considerações finais e referências dos textos das teses e dissertações, foram levantados os seguintes elementos: programa de pós-graduação, Instituição de Educação Superior (IES), área de conteúdo, eixos, problema de pesquisa/objetivos, justificativa apontada pelo autor para utilizar a epistemologia de Fleck, categorias fleckianas utilizadas, referências às obras de Fleck e às pesquisas que utilizaram Fleck e contribuições do referencial epistemológico para a pesquisa em Educação 
em Ciências, apontadas pelo estudo. Estes dados e suas respectivas análises encontram-se a seguir.

\section{A EPISTEMOLOGIA DE FLECK E A PESQUISA EM EDUCAÇÃO EM CIÊNCIAS}

Das 37 pesquisas analisadas, 22 são teses, 14 dissertações desenvolvidas em mestrados acadêmicos e uma dissertação foi produzida em programa de mestrado profissional. Os dados estão na Tabela 3.

Tabela 3 - Volume de trabalhos por IES/Programa

\begin{tabular}{|c|c|c|c|c|}
\hline IES & Programa & Dissertações & Teses & Total \\
\hline \multirow{3}{*}{ UFSC } & Educação & 2 & 4 & 6 \\
\hline & $\begin{array}{c}\text { Educação Científica e } \\
\text { Tecnológica }\end{array}$ & 3 & 11 & 14 \\
\hline & Engenharia Ambiental & - & 1 & 1 \\
\hline UNIJUÍ & Educação nas Ciências & 2 & - & 2 \\
\hline UFPR & Educação & 1 & 1 & 2 \\
\hline UFPA & $\begin{array}{c}\text { Educação em Ciências e } \\
\text { Matemáticas }\end{array}$ & 2 & - & 2 \\
\hline UEL & Filosofia & 1 & - & 1 \\
\hline UFRGS & $\begin{array}{c}\text { Educação Em Ciências Química } \\
\text { Da Vida E Saúde }\end{array}$ & - & 1 & - \\
\hline UFMG & História & 1 & - & 1 \\
\hline UFBA & $\begin{array}{l}\text { Ensino, Filosofia e História das } \\
\text { Ciências }\end{array}$ & 1 & - & 1 \\
\hline UFRN & Educação & 1 & - & 1 \\
\hline UFSCar & Educação & - & 1 & 1 \\
\hline $\begin{array}{l}\text { UFSM/FURG/U } \\
\text { FRGS }\end{array}$ & $\begin{array}{c}\text { Educação em Ciências Química } \\
\text { da Vida e Saúde }\end{array}$ & 1 & - & 1 \\
\hline UNESP & Educação para a Ciência & - & 1 & 1 \\
\hline UTFPR & Ensino de Ciências e Tecnologia* & 1 & - & 1 \\
\hline USP & Ensino de Ciências & - & 1 & 1 \\
\hline & Total & 16 & 21 & 37 \\
\hline
\end{tabular}

Os dados evidenciam a expressiva produção de dissertações e teses geradas no Programa de Educação e Educação Científica e Tecnológica da Universidade Federal de Santa Catarina, com 54\% dos trabalhos. Observa-se também o predomínio de teses de doutorado, equivalendo a $71 \%$ dos trabalhos concentradas nesta instituição.

Ao considerar a área de conteúdo das 37 pesquisas analisadas, identificou-se que 12 trabalhos envolvem Biologia, 8 discutem Ensino de Ciências, 5 a Química, 4 
a Física, 2 a Educação Profissional. As disciplinas de Ciências e Biologia, Educação Ambiental, Educação em Saúde envolvem um trabalho cada. Também identificamos que um trabalho analisa as pesquisas sobre livros didáticos e em outro todas as disciplinas do Ensino Médio são analisados.

Os trabalhos foram aglutinados em torno de seis eixos, dos quais cinco foram definidos por Lorenzetti (2008), quais sejam: Formação de Professores, Currículo, Emergência de um Fato Científico, Análise da Produção Acadêmica e Relação de Fleck com outros autores. No desenvolvimento da pesquisa identificamos um eixo emergente, que denominamos Análise de Materiais Didáticos. Apresentamos a seguir uma caracterização de cada eixo:

- Formação de professores: estudos que analisam o trabalho docente a partir de uma investigação dos discursos, conhecimentos e práticas efetivadas, envolvendo tanto a formação inicial como a continuada. Focam na identificação de coletivos de pensamento, de estilos de pensamento e na circulação de ideias entre os coletivos de pensamento.

- Currículo: trabalhos que analisam os currículos da Educação Básica e Educação Superior, focando em seus componentes, nas práticas profissionais e na articulação teoria e prática. Analisam as concepções epistemológicas, educacionais e de currículo presentes nas propostas curriculares, mapeando estilos e coletivos de pensamento.

- Análise sobre a emergência de um fato científico: trabalhos que fazem um resgate e discussões sobre o surgimento de determinados fatos científicos, o processo de produção de conhecimento, o contexto e as condições da produção, a dimensão histórica e social, os modos de interpretar e compreender um fenômeno, envolvendo a utilização das categorias de instauração, extensão e transformação de Estilos de Pensamento e o papel da circulação intracoletiva e intercoletiva de ideias.

- Relação de Fleck com outros autores: trabalhos que utilizam Fleck como referência, estabelecendo relações com outros autores, discutindo a concepção de ciência, cultura, método da ciência, motivações sociais, entre outros.

- Análise de produção acadêmica: trabalhos que analisam a produção científica em determinada área do conhecimento a partir de dissertações e teses defendidas em programas de pós-graduação, de trabalhos apresentados em eventos ou publicados em periódicos. Estudos que explicitam a constituição da área em estudo, os coletivos de pensamento e os estilos de pensamento que desenvolveram a área do conhecimento.

- Análise de materiais didáticos: trabalhos que analisam a estrutura e o conteúdo dos materiais didáticos, identificando elementos que caracterizam estilos de pensamento, coletivos de pensamento, a circulação de conhecimentos e práticas.

Com base nestas categorias foram analisadas as 37 pesquisas que abarcam a área de conhecimento Educação em Ciências, sendo que 14 discutem Formação de professores, 10 estudos englobam o eixo Emergência de um fato científico, 7 envolvem análises sobre a Produção acadêmica, 5 realizam Estudos sobre o Currículo e um trabalho Análise de Materiais Didáticos. O eixo Relação de Fleck com outros autores não foi evidenciado no período analisado. Nesta pesquisa não localizamos três trabalhos que pertencem aos eixos Formação de Professores, 
Análise da Produção Acadêmica e Currículo. Dados mais específicos dos 34 trabalhos analisados são apresentados a seguir.

No eixo Formação de professores, foram aglutinados 13 estudos dos seguintes autores: Delizoicov (1995), Lambach (2007), Muenchen (2010), Oda (2012), Queirós (2012), Niezwida (2012), Souza (2013), Lambach (2013), Brandao (2013), Gonçalves (2014), Leonel (2015), Souza (2015) e Macedo (2015).

O estudo de Delizoicov (1995) identifica Estilos de Pensamento dos professores de Ciências do Ensino Fundamental, ao analisar sua interação com os livros didáticos. Lambach (2007) identifica Estilos de Pensamento dos professores de Química que atuam em programas de Educação de Jovens e Adultos em escolas públicas do Paraná. O estudo de Muenchen (2010) busca caracterizar os processos investigativos que culminaram na proposição de uma estrutura didáticopedagógica ao Ensino de Ciências denominada de "Três Momentos Pedagógicos" (DELIZOICOV; ANGOTTI; PERNAMBUCO, 2002). Investigou-se, também, o processo de disseminação dessa dinâmica por um grupo de docentes da Universidade Federal de Santa Maria que atua na formação de professores de Ciências. Ao realizar esse percurso, o estudo utiliza intensamente as categorias circulação intracoletiva e circulação intercoletiva de ideias. Oda (2012) pesquisou a constituição e a prática pedagógica de professores universitários para o exercício da atividade docente em Microbiologia e Parasitologia, investigando como esta atividade poderia contribuir para reduzir agravos à saúde causados por organismos parasitas. A tese de Queirós (2012) realiza uma leitura dos trabalhos de James Prescott Joule, mostrando possíveis contribuições desta leitura no processo de articulação das culturas científica e humanística, com enfoque na formação de professores universitários em uma perspectiva transformadora. A construção de uma estratégia didática aponta para a efetividade da circulação intercoletiva e intracoletiva, que está associada à "tomada de consciência" das complicações presentes na construção do conhecimento científico de Joule por um grupo de professores. Niezwida (2012) investiga como os processos de formação docente na área de Educação Tecnológica podem propiciar a transformação nesta educação. Para a autora, a convergência dos pressupostos transformadores de Freire e Fleck permitem indicar a necessidade e a possibilidade de transformação do Estilo de Pensamento dominante em Educação Tecnológica, através de processos de formação continuada dos professores, assim como dos agentes formadores de novos professores. Souza (2013), em sua dissertação de mestrado, identificou e problematizou compreensões sobre a Sustentabilidade Ambiental de um grupo de professores de química da Rede Pública de Ensino do município de Florianópolis/SC, evidenciando a maneira de organizar o ensino, visando a abordagem de assuntos ambientais nesta disciplina. Lambach (2013), em sua tese, destaca as implicações que uma formação permanente fundamentada nos princípios dialógico-problematizadores freireanos trazem à prática docente de professores de química para atuação na Educação de Jovens e Adultos (EJA) e discute as contribuições da epistemologia da Ciência na proposição de uma metodologia dialógico-problematizadora fundamentada na pedagogia freireana de modo a superar as dificuldades recorrentes na área de ciências da natureza. 0 estudo de Brandao (2013), a partir do discurso do professor formador, identifica possíveis modelos pedagógicos e caracteriza estilos de pensamento presentes no curso de licenciatura em física do IFRN. Gonçalves (2014) analisa como a circulação 
de ideias sobre biodiversidade ocorrem nas práticas pedagógicas de professores de Ciências e Biologia com base nas abordagens Ciência, Tecnologia, Sociedade e Patrimonial Ambiental. A tese de Leonel (2015) reflete sobre quais contribuições uma proposta metodológica, no âmbito da formação continuada, para professores de Física, pode oferecer no sentido de atender as demandas presentes na formação e na prática docente no contexto das escolas públicas estaduais de Santa Catarina. A partir das categorias Estilo de Pensamento, Coletivo de Pensamento, Circulações Intra e Intercoletiva e Complicações os professores de física são vistos como um coletivo que pode ser formado por distintos grupos e que se relacionam com outros coletivos. Souza (2015) discute as possibilidades que a Epistemologia de Ludwik Fleck pode trazer para o enfrentamento das lacunas presentes na Formação Inicial de Professores de Ciências, situada sócio e historicamente em um contexto com fragmentação de saberes e que não contribui para a formação de um cidadão crítico. Por fim, a tese de Macedo (2015) buscou responder como as concepções sobre a natureza da ciência, a aprendizagem e o ensino que os professores licenciados em Física pela UFBA têm e transmitem, influenciam a aplicação dos fundamentos do Ensino de Ciências por Investigação às suas atividades de ensino.

Essas pesquisas buscam, cada uma a seu modo, identificar Estilos de Pensamento a partir da análise de concepções educacionais e de práticas pedagógicas.

No eixo Emergência de um fato científico foram classificados dez estudos: Leite (2004), Delizoicov, (2002), Scheid (2006), Lima (2007), Bertoni (2007), Tomio (2012), Tréz (2012), Bertoni (2012), Chaves (2015) e Luiz (2015).

A tese de Leite (2004) identificou e analisou a visão de ciência e a dimensão histórica presente nos livros de genética utilizados no curso de Ciências Biológicas da UFSC. Uma análise epistemológica de um episódio histórico (caso de Mendel) foi realizada para contrapor e superar a visão empirista predominante nos livros e na educação científica em geral. O estudo de Delizoicov (2002) analisou o conhecimento sobre o movimento do sangue no corpo humano, considerando os contextos de sua produção e de sua disseminação. Scheid (2006) investigou aspectos epistemológicos presentes na história de um fato científico e as contribuições proporcionadas pela discussão desses aspectos no processo de ensino e de aprendizagem da Biologia, particularmente da Genética, na formação inicial de professores de Ciências Biológicas. Lima (2007) analisou o processo de planejamento e implantação do Parque Natural Municipal de Lages - SC, com ênfase na Conservação dos Recursos Hídricos e na percepção da comunidade. Bertoni (2007) identificou e fundamentou estilos de pensamento biológico que historicamente predominaram no modo de interpretar e compreender o fenômeno vida, objeto de estudo da Biologia. Tomio (2012) investigou quais as condições de produção da escrita de cientistas podem ser constitutivas do desenvolvimento de conhecimentos científicos e de que modo seus condicionantes podem orientar o funcionamento e/ou análise da escrita de estudantes em aulas de ciências na escola. Tréz (2012) identificou e caracterizou em sua tese os estilos de pensamento em relação ao uso de animais como modelo pelas ciências biomédicas, o perfil potencialmente inovador ou tradicional de docentes e discentes atuantes nas áreas das Ciências Biológicas e da Saúde, em relação ao uso de animais no ensino e na pesquisa, os estilos de pensamento 
operantes entre docentes vinculados a IFES, atuando nas áreas de Ciências Fisiológicas e Farmacêuticas e também caracterizou possíveis relações entre o estilo de pensamento encontrado entre docentes, com os perfis potencialmente inovadores ou tradicionais de pós-graduandos e graduandos de áreas de Ciências Biológicas e da Saúde. Bertoni (2012) investigou os estilos de pensamento que historicamente predominaram e contribuíram para a emergência de concepções históricas de vida. Chaves (2015) teve como problema responder como novas definições da saúde impactaram o campo da educação sanitária, destacando a interferência e inserção de coletivos na educação sanitária. Por fim, a dissertação de Luiz (2015) analisou um episódio da História da Ciência, o da dupla hélice.

Esses estudos, em seus distintos recortes, fazem um resgate e uma análise histórico-epistemológica do processo de produção de determinado conhecimento. Ao realizar esse percurso, explicitam Estilos e Coletivos de Pensamento, especialmente os estudos de Leite (2004) e Scheid (2006), que adicionam a esse foco o desafio de identificar, na trajetória de produção do conhecimento, elementos que possibilitam aos professores em formação uma compreensão mais adequada sobre a natureza da ciência.

No eixo Análise da produção acadêmica foram aglutinados seis estudos; Slongo (2004), Lorenzetti (2008), Mezalira (2008), Emmel (2011), Hoffmann (2012) e Milaré (2013).

A tese de Slongo (2004) analisou a produção acadêmica brasileira em Ensino de Biologia desenvolvida no período de 1972 a 2000, buscando localizar grupos e tendências de pesquisa que marcaram esse período, bem como as circunstâncias sob as quais essas tendências predominaram, foram desenvolvidas e transformadas, levando a área ao atual estado do conhecimento. $O$ estudo de Lorenzetti (2008), utilizando as categorias fleckianas como instrumento de análise da produção acadêmica em Educação Ambiental desenvolvida nos programas de Pós-Graduação no Brasil, caracterizou os Estilos de Pensamento dos membros dos círculos esotérico e exotérico da Educação Ambiental. A pesquisa de Mezalira (2008) centrou-se em investigar e caracterizar coletivos de pesquisadores do pensamento sobre CTS referenciados no Brasil. Emmel (2011) analisou eixos teóricos que estão refletidos nas pesquisas sobre o livro didático e que estilos e coletivos de pensamento constituem estas pesquisas. A dissertação de Hoffmann (2012) buscou caracterizar trabalhos brasileiros que tratam de analogias e metáforas no ensino de Biologia, identificando coletivos de pesquisadores que dedicam suas investigações ao estudo do tema. Milaré (2013) buscou destacar características das pesquisas em ensino de química produzidas entre os anos de 2006 e 2009 nos programas de Pós-graduação da USP nas áreas de educação, química e ensino de ciências.

Tais pesquisas caracterizam-se como estudos histórico-epistemológicos que, ao analisar a produção acadêmica nas respectivas áreas de conhecimento e específicos recortes temporais, identificam Estilos e Coletivos de Pensamento. Isso acontece principalmente nos estudos de Slongo (2004) e Lorenzetti (2008) que, ao explicitarem os Estilos e Coletivos de Pensamento, descrevem seu processo de instauração, extensão e transformação. Além disso, as categorias de circulação intracoletiva e intercoletiva de ideias foram amplamente utilizadas em todos os estudos deste eixo. 
No eixo currículo foram classificados quatro trabalhos: Leal (2013), Alves (2014), Nonenmacher (2014) e Giacomini (2014).

A tese de Leal (2013) discute os limites e as possibilidades de conhecimentos e práticas disseminados por professores de Química nos processos formativos dos Técnicos, referentes às compreensões de educação profissional, meio ambiente, saneamento e ensino de Química, com vistas à adoção de uma perspectiva de formação Crítico-Transformadora. Alves (2014) procura compreender as possíveis manifestações de obstáculos gnosiológicos e que se constituem como limites para a implementação de um currículo crítico de ciências. Fleck contribui especialmente para a compreensão do modo de pensar social e culturalmente compartilhado pelo coletivo de educadores. Nonenmacher (2014), ao analisar um curso de licenciatura em Química, dentro de uma proposta de currículo integrado, procura compreender que "conhecimentos de professor" alguns componentes curriculares (Práticas Profissionais Integradas) proporcionam aos seus licenciandos. Ao refletir sobre Estilos de Pensamento dos licenciandos, identifica matizes destes, na perspectiva da constituição do professor investigativo e colaborativo. Giacomini (2014), ao destacar a relevância que novas configurações curriculares, baseadas na perspectiva crítica e no contexto social, têm de deflagrar um processo de transformações profundas, abalando o estilo de pensamento curricular linear vigente, analisa avanços alcançados por professores nas implementações curriculares do Ensino Médio regular e EJA, na perspectiva da abordagem temática.

Esses estudos buscam discutir projetos curriculares e práticas formativas que contribuem para a formação profissional, em uma perspectiva crítica de currículo.

No eixo Análise de Materiais Didáticos foi classificado um único estudo, de Yamazaki (2015). O autor investiga a estrutura didática de livros textos de Física Básica do Ensino Superior ou manuais de Física Básica, por meio de análise detalhada de exemplares significativos, com o objetivo de identificar e debater uma tradição do ensino desta disciplina. As noções de habitus, de espírito científico e de estilo de pensamento, de Bordieu, Bachelard e Fleck, respectivamente, foram utilizadas pelo autor para a compreensão de pensamentos e ações que estão legitimadas em determinados coletivos de indivíduos.

Conforme já destacado, para Fleck $(1986 ; 2010)$ o conhecimento deriva de uma interação entre o sujeito e o objeto, intercedida por uma dimensão que é social e culturalmente determinada. Nesse sentido, propõe que o processo de produção de conhecimento se concretiza nessa interação do sujeito e objeto, mediado pelo que denomina de Estilo de Pensamento e no interior de um Coletivo de Pensamento.

De acordo com Fleck $(1986 ; 2010)$, a produção do conhecimento caracterizase como um processo que envolve instauração, extensão e transformação de estilos de pensamento. $O$ processo de instauração de um estilo de pensamento decorre do enfrentamento de um problema por mais de um pesquisador, ou seja, por um coletivo. É importante enfatizar que a identificação de um particular estilo de pensamento, bem como suas possíveis transformações se faz com a contribuição de resgates históricos, conforme argumentação de Fleck (1986; 2010).

A perspectiva fleckiana também tem fundamentado análises da produção contemporânea. 70\% dos trabalhos analisados (DELIZOICOV, 1995; SLONGO, 2004; 
BERTONI, 2007; LAMBACH 2007; MEZALIRA, 2008; LORENZETTI, 2008; MUENCHEN, 2010; EMMEL, 2011; NIEZWIDA, 2012; TRÉZ, 2012; ODA, 2012; BRANDÃO, 2013; SOUZA, 2013; MILARÉ, 2013; LAMBACH, 2013; LEAL, 2013; NONENMACHER, 2014; HOFFMANN, 2014; GONÇALVES, 2014; GIACOMINI, 2014; LEONEL, 2015; CHAVES, 2015; MACEDO, 2015 e SOUZA, 2015) abarca análises de aspectos relativamente contemporâneos se comparados com a produção do conhecimento que foi objeto das análises histórico-epistemológicas de episódios que já fazem parte da História da Ciência, como os estudos sobre o modelo de Harvey referente à circulação sanguínea (DELIZOICOV; 2002), sobre as Leis de Mendel (LEITE, 2004), sobre o DNA (SCHEID, 2006), sobre a dupla hélice (LUIZ, 2015) ou de resgates históricos, como a pesquisa referente a produção da escrita dos cientistas Müller e Darwin (TOMIO, 2012), ao estudo do trabalho do cientista James Prescott Joule (QUEIRÓS, 2012) e ao surgimento do conceito vida (BERTONI, 2012).

Os demais estudos analisados, referenciados em Fleck, embora tenham caracterizado estilos de pensamento e dinâmicas de implementação e mudança relativas aos focos que investigaram, não tiveram como objetivo, propriamente, realizar uma análise sobre a produção do conhecimento.

Com relação às justificativas que levaram os pesquisadores a optar pelo aporte epistemológico de Fleck, os estudos destacam, com ênfase, que essa perspectiva possibilitou:

- identificar o caráter sócio-histórico-cultural da produção do conhecimento (LEITE, 2004; DELIZOICOV, 2002; SCHEID, 2006, LORENZETTI, 2008; YUDI, 2012; MILLARÉ, 2013; ALVES, 2014; SOUZA, 2015; MACÊDO, 2015);

- identificar e caracterizar modos de conceber e atuar na pesquisa e no ensino, de acordo com uma perspectiva histórica que inclui o tempo presente. De um modo geral, com maior ou menor ênfase, as 34 pesquisas analisadas atribuem esse potencial à epistemologia de Fleck;

- identificar a necessidade do debate epistemológico na formação inicial e continuada de professores (LAMBACH, 2013; SOUZA, 2015; YAMAZAKI, 2015);

- compreender a interação dos coletivos de cientistas e, neste processo, o papel da circulação de conhecimentos e práticas na produção do conhecimento (DELIZOICOV, 2002; SLONGO, 2004; LEITE, 2004; SCHEID, 2006; BERTONI, 2007 e 2012; LORENZETTI, 2008; MUENCHEN, 2010; EMMEL, 2011; TOMIO, 2012; HOFFMANN, 2012; MILLARÉ, 2013; BRANDÃO, 2015);

- compreender a interação dos coletivos de educadores e educandos e, neste processo, a circulação de conhecimentos e práticas e seu papel nas transformações ocorridas/necessárias na formação e na prática dos professores da área e/ou nas práticas pedagógicas e estruturas curriculares que favorecem a disseminação da cultura científica (LAMBACH, 2007; MUENCHEN, 2010; EMMEL, 2011; NIEZWIDA, 2012; QUEIRÓS, 2012; SOUZA, 2013; GONÇALVES, 2014; GIACOMINI, 2014; NONENMACHER, 2014; BRANDÃO, 2015);

- identificar/conhecer e caracterizar pensamentos/concepções (educacionais e epistemológicas) e práticas pedagógicas presentes na formação e na atuação dos professores, bem como, nos materiais didáticos para o ensino das Ciências 
Naturais (DELIZOICOV, 1995; LAMBACH, 2007; BERTONI, 2007; MUENCHEN, 2010; YUDI, 2012; LEAL, 2012; LEONEL, 2015; MACÊDO, 2015).

Observou-se que as categorias

epistemológicas

de $\quad$ Fleck

"estilo de pensamento" e "coletivo de pensamento" foram utilizadas pelos 34 estudos analisados, contudo, essas categorias comparecem nas pesquisas de distintos modos e com distintas ênfases. Após uma década, em 2004, surgem os primeiros diálogos destas pesquisas com as categorias "círculos esotéricos e exotéricos" e "circulação intra e intercoleiva de ideias". A presença destas categorias se intensifica nas produções desenvolvidas no período posterior, sendo que aproximadamente $50 \%$ (18 estudos) das pesquisas dialogam e buscam identificar os distintos Coletivos de Pensamento envolvidos nos particulares recortes da educação científica investigados, como também, a dinâmica de comunicação entre eles. Mais recentemente, em 2012, surgem os primeiros estudos que utilizam a categoria "complicações" em suas análises epistemológicas. São aproximadamente $30 \%$ dos estudos analisados (dez pesquisas) que investigam as complicações enfrentadas pelos distintos coletivos de pensamento na disseminação de seus conhecimentos e práticas. Esses dados mostram que as pesquisas tem avançado na utilização das categorias fleckianas e na sua aplicação em diferentes contextos. A disseminação e uso dessas categorias epistemológicas para investigar diferentes objetos na área da Educação em Ciências reflete seu potencial.

Partindo do pressuposto que um Coletivo de Pensamento compartilha conhecimentos e práticas, as quais caracterizam o Estilo de Pensamento em vigor, foram investigadas referências bibliográficas utilizadas pelas pesquisas analisadas e que abordam a epistemologia de Fleck $(1986 ; 2010)$. Esse dado é relevante na medida em que explicita o compartilhamento de elementos teóricos e metodológicos pela pesquisa em Educação em Ciências. Identificou-se que o livro de Fleck na versão espanhola (FLECK, 1986) e na portuguesa (FLECK, 2010) foi citado em 23 trabalhos cada, constatando-se que a partir de 2010 com a publicação do livro em português há uma redução nas citações da versão espanhola, seguido da introdução que Schãfer e Schnelle $(1986 ; 2010)$ fazem na introdução à obra do autor, a qual também foi citada em 20 estudos. Observa-se que nos trabalhos mais recentes há uma redução na utilização deste referencial. Os textos de Ilana Löwy (1994a, 1994b, 2004), grande divulgadora do pensamento epistemológico de Fleck, foram citados por 19 das 34 pesquisas analisadas. Além disso, com sete citações, destacam-se os artigos organizados por Cohen e Schnelle (1986) na obra Cognition and Fact. Também foram identificados outros 359 textos que fazem referência à epistemologia de Fleck (1986; 2010), dos quais, 118 são teses, dissertações e artigos publicados em periódicos e anais/atas de eventos.

A tese de Da Ros (2000) foi citada por 16 textos, e as de Cutolo (2001), Leite (2004) em 14, a dissertação de Delizoicov (1995) em 12 e a tese de Delizoicov (2002) por 10. Com oito citações, encontram-se a tese de Muenchen (2010) e Scheid (2006), com seis a tese de Leite (2004) e de Slongo (2004) e a dissertação de Parreira (2006). Com cinco as teses Pfuetzenreiter (2003) e Lorenzetti (2008). Por sua vez, o artigos de Delizoicov et al. (2002) foi citado em 23 estudos, o de Leite, Ferrari e Delizoicov (2001) em 14, o de Gonçalves, Marques e Delizoicov (2007) em 9 estudos. Outro dado que chama a atenção é a quantidade de citações, presentes nas dissertações e teses que utilizaram a epistemologia de Fleck, feitas 
pelos autores das pesquisas analisadas. Os estudos de Lorenzetti (2008) e Muenchen (2010), Milaré (2013) localizaram a maioria das dissertações e teses desenvolvidas nos programas de pós-graduação. Já os estudos de Lima (2007), Mezalira (2008), Oda (2012) e Souza (2013) citaram poucos trabalhos envolvendo a epistemologia fleckiana.

Ao analisar as referências compartilhadas na produção acadêmica em Educação Ambiental, Lorenzetti (2008, p. 349) identificou a "[...] incipiente Circulação Intracoletiva de Ideias, principalmente em relação às referências das distintas dissertações e teses de Educação Ambiental desenvolvidas nos programas de Pós-Graduação no Brasil". Argumenta o autor para que "haja maior disseminação dos conhecimentos e práticas que estão sendo vinculadas nestas pesquisas é necessário referenciar e discutir o que já se produziu na área, ampliando as discussões [...]. Uma intensificação no uso mais compartilhado de referências potencializaria a extensão do Estilo de Pensamento" (LORENZETTI, 2008, p. 349). Da mesma forma, conforme destacado, pode-se verificar que alguns autores das pesquisas analisadas não referenciaram trabalhos assemelhados, pouco contribuindo para a disseminação e ampliação da epistemologia de Fleck. Entende-se que estudos que se referem às pesquisas já realizadas podem contribuir para potencializar novos estudos, balizados pelas contribuições epistemológicas do autor.

Quanto aos aspectos metodológicos presentes nos trabalhos analisados, identificamos o predomínio da pesquisa documental e bibliográfica. Os principais instrumentos de coleta de dados utilizados foram os questionários e entrevistas, que possibilitaram, tanto resgates históricos quanto a explicitação de concepções e práticas que possibilitaram identificar e caracterizar Estilos de Pensamento, Coletivo de pensamento, como também, a circulação de ideias, conhecimentos e práticas entre os círculos esotérico e exotérico que compõe a grande a área de Educação em Ciências.

Com relação à importância do referencial epistemológico fleckiano para os estudos analisados, prevaleceram os argumentos de que contribuiu para:

- uma melhor compreensão do processo de produção e evolução do conhecimento;

- uma adequada explicitação das características destes conhecimentos;

- a identificação e leitura crítica dos diferentes estilos de pensamento e coletivos de pensamento presentes na histórica de uma área do conhecimento ou nos diferentes materiais curriculares e didáticos analisados, bem como, nos diferentes espaços e processos formativos;

- identificar a circulação de conhecimentos e práticas em diferentes âmbitos (intra e inter coletivos), de modo a intercambiar sentidos e modos de atuar, como também, explicitar complicações que necessitam ser enfrentadas para que hajam transformações, para além dos espaços formativos.

\section{CONSIDERAÇÕES FINAIS}


O estudo realizado teve o objetivo de identificar em que momento Fleck se estabeleceu como um referencial importante para a pesquisa, especialmente na área de Educação em Ciências e qual a relação que a pesquisa desenvolvida na área estabeleceu com esse referencial. Considerando as fontes subsidiárias deste estudo, os dados revelaram que foi em meados da década de 1990 que sugiram no Brasil os primeiros estudos subsidiados por pela matriz epistemológica de Ludwik Fleck (1986; 2010). Mostraram também que há uma concentração de trabalhos em instituições do Sul do Brasil, notadamente na Universidade Federal de Santa Catarina e na área de Educação em Ciências, estando o maior volume de estudos concentrados no eixo "formação de professores" e "emergência de um fato científico", seguido pelos estudos sobre a "análise da produção acadêmica", "currículo" e "análise de material didático".

Com relação às contribuições da epistemologia de Fleck para a pesquisa na área de Educação em Ciências, houve destaque para as seguintes justificativas: possibilita compreender a constituição de uma área do conhecimento; explicitar o caráter sociológico tanto da produção quanto da disseminação do conhecimento; identificar as condições para a instauração de um estilo de pensamento ligado à ciência; compreender a importância da comunicação intra e intercoletiva no estabelecimento e transformação de um estilo de pensamento; analisar o peso da formação para o ingresso em um estilo de pensamento; melhor compreender a relação teoria e prática na formação dos professores; refletir sobre a prática pedagógica dos professores; desenvolver alternativas para a inserção da história da ciência nos currículos da graduação.

Os dados mostraram que vem se consolidando no Brasil uma comunidade nacional de investigadores em Educação em Ciências que tem a epistemologia de Fleck como horizonte de análise.

O estudo não teve a pretensão de dimensionar o alcance ou o impacto da incorporação dos pressupostos epistemológicos fleckianos nesta produção científica, mas explicitar o diálogo que a área de Educação em Ciências tem feito com a epistemologia de Fleck. Assim, a perspectiva com que foi realizada essa análise visou, sobretudo, apresentar um panorama que possa contribuir para novas reflexões. 


\title{
The growing presence of Ludwik Fleck's epistemology on science education research in Brazil
}

\begin{abstract}
This study centers on the reception of Ludwik Fleck's epistemology by Science Education research in Brazil. Eighty-nine dissertations and theses have been analyzed from 1995 to 2015, thirty-seven of which discuss Science Education. The data point to Fleck's epistemology as a preferential theoretical referential for the most diverse fields of knowledge. The first studies came about in the 1990's and there is a concentration of works on Science Education at the Federal University of Santa Catarina. In an in-depth analysis in thirty-four papers from six axes, which discuss the Education in Sciences. The study identified that the largest concentration of axes is in the "teacher training" and "emergence of a scientific fact". The significant contribution of the epistemological categories "thought style", "thought collective" "intra and intercollective circulation if ideas" stand out in the process of producing knowledge into the focus area.
\end{abstract}

KEYWORDS: Fleck's epistemology. State of knowledge. Science education. Theses and dissertations. 


\section{REFERÊNCIAS}

ANDRÉ, M. E. D. A. Formação de Professores no Brasil (1990 - 1998). Série Estado do Conhecimento, n. 6 Brasília: MEC/Inep/Comped, 2002.

CUTOLO, L. R. A. Estilo de pensamento em educação médica: um estudo do currículo do curso de graduação em medicina da UFSC. 2001. Tese (Doutorado em Educação) -Universidade Federal de Santa Catarina, Florianópolis, 2001

DA ROS, M. A. Estilo de pensamento em educação médica: um estudo da produção da FSP-USP e ENSP- FIOCRUZ entre 1948 e 1994, a partir de epistemologia de Ludwik Fleck. 2000. Tese (Doutorado em Educação) Universidade Federal de Santa Catarina, Florianópolis, 2000.

DELIZOICOV, D. et al. Sociogênese do conhecimento e pesquisa em ensino: contribuições a partir do referencial fleckiano. Caderno Brasileiro do Ensino de Física, Florianópolis, v. 19, número especial, p. 52-69, jun. 2002.

DELIZOICOV, D.; ANGOTTI, J. A.; PERNAMBUCO, M. M. Ensino de Ciências: fundamentos e métodos. São Paulo: Cortez, 2002.

EMMEL, R. Estado da Arte e coletivos de pensamento na pesquisa sobre o livro didático no Brasil. 2011. Dissertação. (Mestrado em Educação nas Ciências) Universidade Regional do Noroeste do Estado do Rio Grande do Sul - Unijuí, 2011.

FERREIRA, N. S. As pesquisas denominadas "Estado da Arte". Educação e Sociedade, Unicamp, n.79, p. 257-272, 2002.

FLECK, L. La génesis y el desarrollo de um hecho científico. Madrid: Alianza Editorial, 1986.

Gênese e desenvolvimento de um fato científico. Belo Horizonte: Fabrefactum. 2010.

GAMBOA, S. S. Pesquisa em Educação: métodos e epistemologias. Chapecó: Argos, 2008.

GONÇALVES, F. P.; MARQUES, C. A.; DELIZOICOV, D. O desenvolvimento profissional dos formadores de professores de química: contribuições 
epistemológicas. Revista Brasileira de Pesquisa em Educação em Ciências, Belo Horizonte, v.7, n.3, 2007.

LEITE, R. C. M.; FERRARI, N; DELIZOICOV, D. A história das leis de Mendel na perspectiva fleckiana. Revista Brasileira de Pesquisa em Educação em Ciências, v. 1,n. 2, p. 97-108, mai/ago. 2001.

LORENZETTI, L. Estilos de pensamento em educação ambiental: uma análise a partir das dissertações e teses. 2008. Tese (Doutorado em Educação Científica e Tecnológica) - Universidade Federal de Santa Catarina, Florianópolis, 2008.

LORENZETTI, L.; MUENCHEN, C.; SLONGO, I. I. P. A recepção da epistemologia de fleck pela pesquisa em educação em ciências. Ensaio - Pesquisa em Educação em Ciências, Belo Horizonte, v. 13, n. 3, p. 181-197, 2013.

LÖWY, I. Ludwik Fleck e a presente história das ciências. Manguinhos - História, Ciências, Saúde, Rio de Janeiro: Fiocruz, v. 1, n. 1, 1994a.

Fleck e a historiografia recente da pesquisa biomédica. In: PORTOCARRERO, V. (Org.) Filosofia, história e sociologia das ciências: abordagens contemporâneas. Rio de Janeiro: Fiocruz, 1994b.

Introduction: Ludwik Fleck's epistemology of medicine and biomedical sciences. Stud. Hist. Phil. Biol \& Biomed. Sc., n. 35, p. 437-445, 2004.

MARQUES, C. A. Estilos de pensamento de professores italianos sobre a Química Verde na educação em química escolar. Revista Electónica de Enseñanza de las Ciências, v. 11, n. 2, 2012.

MILARÉ, T. A pesquisa em Ensino de Química na Universidade de São Paulo: estudos das Dissertações e Teses (2006 - 2009) sob a perspectiva fleckiana. 2013. Tese (Doutorado em Educação) - Universidade de São Paulo, 2013.

MORAES, R.; GALIAZZI, M. do C. Análise Textual Discursiva. Ijuí: Ed. Unijuí, 2013.

MUENCHEN, C. Disseminação dos três momentos pedagógicos: um estudo sobre práticas docentes na região de Santa Maria - RS. 2010. Tese (Doutorado em Educação Científica e Tecnológica) - Universidade Federal de Santa Catarina, Florianópolis, 2010. 
PARREIRAS, M. M. M. Ludwik Fleck e a historiografia da ciência: diagnóstico de um estilo de pensamento segundo as Ciências da Vida. 2006. Dissertação (Mestrado em História) - Universidade Federal de Minas Gerais, 2006.

PFUETZENREITER, M. R. O ensino da medicina veterinária preventiva e saúde pública nos cursos de medicina veterinária: estudo de caso realizado na Universidade do Estado de Santa Catarina. 2003. Tese (Doutorado em Educação) - Universidade Federal de Santa Catarina, Florianópolis, 2003.

QUEIRÓS, E. P. de; NARDI, R. Um panorama da epistemologia de Ludwik Fleck na pesquisa em ensino de ciências. In: ENCONTRO DE PESQUISA EM ENSINO DE FÍSICA, 11., 2008, Curitiba. Anais... Curitiba: SBF, 2008. p. 1-11.

ROMANOWSKI. J. P.; ENS, R. T. As pesquisas denominadas do tipo "estado da arte" em educação. Diálogos Educ. Curitiba, v. 6, n. 19, p. 37-50, set/dez, 2006.

SCHÄFER, L.; SCHNELLE, T. Los fundamentos de la visión sociológica de Ludwik Fleck de la teoria de la ciência. In: FLECK, L. La gênesis y el desarrollo de um hecho científico. Madrid: Alianza Editorial, 1986

SLONGO, I. I. P. A produção acadêmica em ensino de biologia: um estudo a partir de teses e dissertações. 2004. Tese (Doutorado em Educação) - Universidade Federal de Santa Catarina, Florianópolis, 2004.

SOARES, M.B.; MACIEL, F. Alfabetização. Série Estado do Conhecimento, n. 1 Brasília: MEC/Inep/Comped, 2000.

\section{RELAÇÃO DAS DISSERTAÇÕES E TESES ANALISADAS}

ALVES, A. H. B. Manifestações de obstáculos gnosiológicos para a seleção de conteúdos na implementação de um currículo crítico em Ciências. 2014. Dissertação (Mestrado em Educação) - Universidade Federal de São Carlos, Sorocaba, 2014.

AMORIM, M. Â. L. Parâmetros curriculares nacionais para o ensino médio e professores de biologia: dificuldades de interlocução. 2004. Tese (Doutorado em Educação) - Universidade Federal de Santa Catarina, Florianópolis, 2004.

ANJOS, M. de C. R. dos. Fronteiras na construção e socialização do conhecimento científico e tecnológico: um olhar para a extensão universitária. 2014. Tese (Doutorado em Educação Científica e Tecnológica) - Universidade Federal de Santa Catarina, Florianópolis, 2014. 
ARAÚJO, R. L. C. da C. Doenças construção e realidade na formação dos médicos. Objeto Fronteira como instrumento de interação entre diferentes estilos de pensamento. 2002. Dissertação (Mestrado em Educação) - Universidade Federal de Santa Catarina, Florianópolis, 2002.

ARIOLI, I. G. da S. Práticas e estilos de pensamento em promoção de saúde no contexto da atenção básica. 2012. Dissertação (Mestrado em Psicologia) Universidade Federal de Santa Catarina, Florianópolis, 2012.

AUGUSTO, V. G. Um Olhar sobre a LER/DORT no contexto clínico do fisioterapeuta. 2006. Dissertação (Mestrado em Ciências da Reabilitação) Universidade Federal de Minas Gerais, Belo Horizonte, 2006.

BACKES, V. M. S. Estilo de pensamento e práxis na enfermagem: a contribuição do estágio pré-profissional. 1999. Tese (Doutorado em Enfermagem) Universidade Federal de Santa Catarina, Florianópolis, 1999.

BARGUIL, C. M. K. O lugar e o valor da fisioterapia na terapêutica médica: a medicina prática nos primeiros trinta anos do século XX. 2011. Tese (Doutorado em História das Ciências e da Saúde) - Fundação Oswaldo Cruz, Rio de Janeiro, 2011.

BERG, J. K. Para que serve uma enfermaria de clínica médica?: reflexões a partir de um hospital universitário. 2014. Dissertação (Mestrado em Saúde Coletiva) Universidade do Estado do Rio de Janeiro, Rio de Janeiro, 2014.

BERTONI, D. Um estudo dos estilos de pensamento biológico sobre o fenômeno vida. 2007. Dissertação (Mestrado em Educação) - Universidade Federal do Paraná, Curitiba, 2007.

BERTONI, D. Gênese e desenvolvimento do conceito vida. 2012. Tese (Doutorado em Educação) - Universidade Federal do Paraná, Curitiba, 2012.

BISCHOFF, H. F. O estilo de pensamento em medicina estética: reflexões sobre as bases epistemológicas da formação médica. 2009. Dissertação (Mestrado em Educação) - Universidade do Extremo Sul Catarinense, Criciúma, 2009.

BRANDAO, X. S.G. Uma análise da formação de professores de Física do IFRN a partir da epistemologia de Ludwik Fleck. 2013. Dissertação (Mestrado em Educação) - Universidade Federal do Rio Grande do Norte, Natal, 2013. 
CARNEIRO, J. A. C. A teoria comparativa do conhecimento de Ludwik Fleck: comunicabilidade e incomensurabilidade no desenvolvimento das ideias científicas. 2012. Dissertação (Mestrado em Filosofia) - Universidade de São Paulo, São Paulo, 2012.

CAVALLI, C. Reflexões sobre a Educação Física no SUS: uma análise a partir das dissertações e teses. 2009. Dissertação (Mestrado em Educação Física) Universidade Federal de Santa Catarina, Florianópolis, 2009.

CELI, R. C. Estudo sobre estilos de pensamento na Educação Física no contexto do SUS. 2013. Dissertação (Mestrado em Saúde e Gestão do Trabalho) Universidade do Vale do Itajaí, Itajaí, 2013.

CHAVES, B. S. Conhecimento, linguagem e ensino: a educação em saúde na história da ciência (1940-1971). 2015. Tese (Doutorado em História) Universidade Federal de Minas Gerais, Belo Horizonte, 2015.

COSTA, N. L. Estilos de pensamento em acupuntura: uma análise epistemológica. 2009. Dissertação (Mestrado em Saúde) - Universidade do Vale do Itajaí, Itajaí, 2009.

CUNHA, C. E. C. A teoria de William Harvey da circulação do sangue: um traçado histórico do desenvolvimento das concepções, dos conceitos e dos modelos. 2013. Dissertação (Mestrado em Ensino de Ciências da Saúde e do Ambiente) Centro Universitário Plínio Leite, Niterói, 2013.

CURI, L. M. Excluir, isolar e conviver: um estudo sobre a lepra e a hanseníase no Brasil. 2010. Tese (Doutorado em História) - Universidade Federal de Minas Gerais, Belo Horizonte, 2010.

CUTOLO, L.R. A. Estilo de pensamento em educação médica: um estudo do currículo do curso de graduação em Medicina da UFSC. 2001. Tese (Doutorado em Educação) - Universidade Federal de Santa Catarina, Florianópolis, 2001.

DA ROS, M. A. Estilo de pensamento em educação médica: um estudo da produção da FSP-USP e ENSP-FIOCRUZ entre 1948 e 1994, a partir de epistemologia de Ludwik Fleck. 2000. Tese (Doutorado em Educação) Universidade Federal de Santa Catarina, Florianópolis, 2000.

DELIZOICOV, N. C. O professor de ciências naturais e o livro didático. 1995. Dissertação (Mestrado em Educação) - Universidade Federal de Santa Catarina, Florianópolis, 1995. 
DELIZOICOV, N. C. O movimento do sangue no corpo humano: história e ensino. 2002. Tese (Doutorado em Educação) - Universidade Federal de Santa Catarina, Florianópolis, 2002.

DIAS, J. L. Compreensão de professores de matemática sobre números fracionários. 2012. Tese (Doutorado em Educação em Ciências e Matemáticas) Universidade Federal do Pará, Belém, 2012.

DURGANTE, L. P. Expectativas dos indivíduos homeopatas de Itajaí a respeito de sua participação no SUS local. 2006. Dissertação (Mestrado em Saúde Coletiva) Universidade Federal de Santa Catarina, Florianópolis, 2006.

EMMEL, R. Estado da arte e coletivos de pensamento da pesquisa sobre o livro didático no Brasil. 2011. Dissertação (Mestrado em Educação nas Ciências) Universidade Regional do Noroeste do Estado do Rio Grande do Sul, Ijuí, 2011.

FAVORETO, C. A. O. A narrativa na e sobre a clínica na atenção primária: uma reflexão sobre o modo de pensar e agir dirigido pelo diálogo, à integralidade e ao cuidado em saúde. 2007. Dissertação (Mestrado em Saúde Coletiva) - Universidade do Estado do Rio de Janeiro, Rio de Janeiro, 2007.

GIACOMINI, A. Intervenções curriculares na perspectiva da abordagem temática: avanços alcançados por professores de uma escola pública estadual do RS. 2014. Dissertação (Mestrado em Educação em Ciências: Química da Vida e Saúde) Universidade Federal de Santa Maria, (UFSM-FURG-UFRGS), Santa Maria, 2014.

GOMES, D. Etiologia da cárie uma construção do estilo de pensamento. 2002. Dissertação (Mestrado em Saúde Coletiva) - Universidade Federal de Santa Catarina, Florianópolis, 2002.

GONCALVES, A. da C. A circulação de ideias sobre biodiversidade por professores de ciências e biologia nas abordagens CTS e patrimonial ambiental. 2014. Dissertação (Mestrado em Educação em Ciências e Matemáticas) - Universidade Federal do Pará, Belém, 2014.

GONCALVES, L. A. P. Medicina e Enfermagem - saberes e práticas incomensuráveis? Uma abordagem à luz da hermenêutica e dos science studies. 2014. Dissertação (Mestrado em Saúde Coletiva) - Universidade do Estado do Rio de Janeiro, Rio de Janeiro, 2014. 
GUEDES, C. R. A subjetividade como anomalia: estratégias médicas para lidar com os sintomas vagos e difusos em biomedicina. 2007. Tese (Doutorado em Saúde Coletiva) - Universidade do Estado do Rio de Janeiro, Rio de Janeiro, 2007.

GUIMARAES, S. M. Educação física, vivência e experiência corporal. 2002. Dissertação (Mestrado em Educação Física) - Universidade Federal de Santa Catarina, Florianópolis, 2002.

HERMANN, W. Estudo sobre a prática científica de um grupo de pesquisa em educação matemática. 2011. Dissertação (Mestrado em Ensino de Ciências e Educação Matemática) - Universidade Estadual de Londrina, Londrina, 2011.

HOFFMANN, M. B. Analogias e metáforas no ensino de biologia: um panorama da produção acadêmica brasileira. 2012. Dissertação (Mestrado em Educação Científica e Tecnológica) - Universidade Federal de Santa Catarina, Florianópolis, 2012.

KOIFMAN, L. A crítica do modelo biomédico na reformulação curricular do curso de Medicina da Universidade Federal Fluminense. 1996. Dissertação (Mestrado em Saúde Coletiva) - Fundação Oswaldo Cruz, Rio de Janeiro, 1996.

KOSLOWSKI, A. Nas origens da estrutura das revoluções científicas: a influência de Fleck, Polanyi e Quine na filosofia da ciência de Thomas Samuel Kuhn. 2004. Dissertação (Mestrado em Filosofia) - Universidade Federal de Santa Catarina, Florianópolis, 2004.

LAMBACH, M. Atuação e Formação dos Professores de Química na EJA: Características dos Estilos de Pensamento - um olhar a partir de Fleck. 2007. Dissertação (Mestrado em Educação Científica e Tecnológica) - Universidade Federal de Santa Catarina, Florianópolis, 2007.

LAMBACH, M. Formação Permanente de Professores de Química da EJA na Perspectiva Dialógico-Problematizadora Freireana. 2013. Tese (Doutorado em Educação Cientifica e Tecnológica) - Universidade Federal de Santa Catarina, Florianópolis, 2013.

LEAL, A. L. Relações entre Saneamento-Química-Meio Ambiente na Educação Profissional e Tecnológica numa Perspectiva Crítico Transformadora. 2013. Tese (Doutorado em Educação Científica e Tecnológica) - Universidade Federal de Santa Catarina, Florianópolis, 2013. 
LEITE, R. C. M. A produção coletiva do conhecimento científico: um exemplo no ensino de genética. 2004. Tese (Doutorado em Educação) - Universidade Federal de Santa Catarina, Florianópolis, 2004.

LEONEL, A. A. Formação continuada de professores de física em exercício na rede pública estadual de Santa Catarina: lançando um novo olhar sobre a prática. 2015. Tese (Doutorado em Educação Científica e Tecnológica) - Universidade Federal de Santa Catarina, Florianópolis, 2015.

LIMA, L. C. de. Processo de planejamento e implantação do Parque Natural Municipal de Lages - SC com ênfase na conservação de bacias hidrográficas e na percepção da comunidade do entorno. 2007. Tese (Doutorado em Engenharia Ambiental) - Universidade Federal de Santa Catarina, Florianópolis, 2007.

LIMA, L. C. A formação dos professores de ciências: uma abordagem epistemológica. 1999. Dissertação (Mestrado em Educação) - Universidade Federal de Santa Catarina, Florianópolis, 1999.

LIMA, R. A. C. Estilo de pensar no ensino de medicina homeopática. 2003. Tese (Doutorado em Educação) - Universidade Federal de Santa Catarina, Florianópolis, 2003.

LORENZETTI, L. Estilos de pensamento em educação ambiental: um estudo a partir das dissertações e teses. 2008. Tese (Doutorado em Educação Científica e Tecnológica) - Universidade Federal de Santa Catarina, Florianópolis, 2008.

LÜDKE, L. Formação de Docentes para o SUS: um desafio sanitário e pedagógico. 2009. Dissertação (Mestrado em Saúde) - Universidade do Vale do Itajaí, Itajaí, 2009.

LUIZ, C. C. M. A história da dupla hélice interpretada a partir do quadro conceitual de Ludwik Fleck. 2015. Dissertação (Mestrado em Filosofia) - Universidade Estadual de Londrina, Londrina, 2015.

MACEDO, R. S. de. 0 ensino de ciências por investigação e a prática pedagógica de professores licenciados no IF-UFBA. 2015. Tese (Doutorado em Ensino, Filosofia e História das Ciências) - Universidade Federal da Bahia, Salvador, 2015.

MACHADO, N. H. S. O ensinar e o aprender a fazer pesquisa: o real e o desejado. 2008. Dissertação (Mestrado em Educação) - Universidade de Brasília, Brasília, 2008. 
MAEYAMA, M. A. Estilos de Pensamento em Odontologia Social e Preventiva Um estudo da disciplina de Odontologia Social e Preventiva do curso de odontologia da UNIVALI. 2006. Dissertação (Mestrado em Saúde) - Universidade do Vale do Itajaí, Itajaí, 2006.

MAEYAMA, M. A. A escolha da especialidade médica - Estilos de Pensamento. 2015. Tese (Doutorado em Saúde Coletiva) - Universidade Federal de Santa Catarina, Florianópolis, 2015.

MARAVIESKI, M. Homeopatia: uma desconhecida na região Sul II da Associação Brasileira de Educação Médica. 2003. Dissertação (Mestrado em Saúde Pública) Universidade Federal de Santa Catarina, Florianópolis, 2003.

MEZALIRA, S. M. Enfoque CTS no ensino de ciências naturais a partir de publicações em eventos científicos no Brasil. 2008. Dissertação (Mestrado em Educação nas Ciências) - Universidade Regional do Noroeste do Estado do Rio Grande do Sul, ljuí, 2008.

MILARE, T. A pesquisa em ensino de química na Universidade de São Paulo: estudo das dissertações e teses (2006-2009) sob a perspectiva fleckiana. 2013. Tese (Doutorado em Ensino de Ciências) - Universidade de São Paulo, São Paulo, 2013.

MUENCHEN, C. Disseminação dos três momentos pedagógicos: um estudo sobre práticas docentes na região de Santa Maria/RS. 2010. Tese (Doutorado em Educação Científica e Tecnológica) - Universidade Federal de Santa Catarina, Florianópolis, 2010.

NEDER, C. J. Comunidade científica e natureza no pensamento de T. S. Kuhn. 2001. Dissertação (Mestrado em Filosofia) - Universidade do Estado do Rio de Janeiro, Rio de Janeiro, 2001.

NIEZWIDA, N. R. A. Educação Tecnológica Com Perspectiva Transformadora: A Formação docente Na Constituição De Estilos De Pensamento. 2012. Tese (Doutorado em Educação Científica e Tecnológica) - Universidade Federal de Santa Catarina, Florianópolis, 2012.

NOGUEIRA, F. S. Ciência e linguagem: Fleck e o estilo de pensamento como rede de significados na ciência. 2012. Dissertação (Mestrado em História) Universidade Federal de Minas Gerais, Belo Horizonte, 2012. 
NOGUEIRA, M. I. Entre a conversão e o ecletismo: de como médicos brasileiros tornam-se "chineses". 2003. Tese (Doutorado em Saúde Coletiva) - Universidade do Estado do Rio de Janeiro, Rio de Janeiro, 2003.

NONENMACHER, S. E. B. Contribuições da prática profissional integrada na formação inicial de professores. 2014. Tese (Doutorado em Educação em Ciências Química da Vida e Saúde) - Universidade Federal do Rio Grande do Sul, Porto Alegre, 2014.

ODA, W. Y. A docência universitária em biologia e suas relações com a realidade das metrópoles amazônicas. 2012. Tese (Doutorado em Educação Científica e Tecnológica) - Universidade Federal de Santa Catarina, Florianópolis, 2012.

PARREIRAS, M. M. M. Lukwik Fleck e a historiografia da ciência: diagnóstico de um estilo de pensamento segundo as Ciências da Vida. 2006. Dissertação (Mestrado em História) - Universidade Federal de Minas Gerais, Belo Horizonte, 2006.

PFUETZENREITER, M. R. O ensino da medicina veterinária preventiva e saúde pública nos cursos de medicina veterinária: estudo de caso realizado na Universidade do Estado de Santa Catarina. 2003. Tese (Doutorado em Educação) Universidade Federal de Santa Catarina, Florianópolis, 2003.

POLETTO, C. A. R. O processo cognitivo evidenciado nos estilos de pensamento revelados nos saberes e práticas de orientação de monografias na área de odontologia Lages. 2015. Dissertação (Mestrado em Educação) - Universidade do Planalto Catarinense, Lages, 2015.

QUARESMA, S. J. L. A percepção do médico clínico em relação aos pacientes hipocondríacos e poliqueixosos que são atendidos no ambulatório do Hospital Universitário Professor Polydoro Ernani de São Thiago. 2005. Dissertação (Mestrado em Sociologia Política) - Universidade Federal de Santa Catarina, Florianópolis, 2005.

QUEIROS, W. P. d. A articulação das culturas humanísticas e científicas por meio do estudo histórico sociocultural dos trabalhos de James Prescott Joule: Contribuições para a formação de professores universitários em uma perspectiva transformadora. 2012. Tese (Doutorado em Educação para a Ciência) Universidade Estadual Paulista, Bauru, 2012.

SALLES, A. C. de. Nem gênios, nem heróis: a história da ciência em Ludwik Fleck. 2007. Dissertação (Mestrado em História) - Universidade Federal de Minas Gerais, Belo Horizonte, 2007. 
SANTOS, A. L. G. dos. Uma construção dos saberes sobre Epidemia de AIDS: os formulários de notificação de caos em perspectiva (1982 -98). 1999. Dissertação (Mestrado em Saúde Pública) - Fundação Oswaldo Cruz, Rio de Janeiro, 1999.

SANTOS, M. A. M. As diretrizes curriculares e o currículo de graduação em medicina da UNIVALI: construindo a interdisciplinaridade através dos Objetos Fronteiriços e da Epistemologia de Fleck. 2005. Dissertação (Mestrado em Saúde) - Universidade do Vale do Itajaí, Itajaí, 2005.

SANTOS, R. A. dos. Estilos de Pensamento da assistência médica aos pacientes oncológicos na rede pública de saúde do Município do Rio de Janeiro. 2014. Tese (Doutorado em Saúde Coletiva) - Universidade do Estado do Rio de Janeiro, Rio de Janeiro, 2014.

SCHEID, N. M. J. A contribuição da história da biologia na formação inicial de professores de ciências biológicas. 2006. Tese (Doutorado em Educação Científica e Tecnológica) - Universidade Federal de Santa Catarina, Florianópolis, 2006.

SCHVEITZER, M. C. Estilos de Pensamento em Educação em Enfermagem: uma análise da produção científica das Regiões Norte, Nordeste e Centro-Oeste do Brasil. 2010. Dissertação (Mestrado em Enfermagem) - Universidade Federal de Santa Catarina, Florianópolis, 2010.

SILVA, D. S. F. da. O alarme que precisa ser regulado: os debates médicos sobre a fibromialgia na sociedade brasileira de reumatologia entre as décadas de 1990 e 2010. 2014. Dissertação (Mestrado em História das Ciências) - Fundação Oswaldo Cruz, Rio de Janeiro, 2014.

SILVA, E. H. S. da. Estilos de pensamento sobre Biodiversidade em Pesquisas de Educação Ambiental Publicadas no EPEA. 2014. Dissertação. (Mestrado em Educação em Ciências e Matemáticas) - Universidade Federal do Pará, Belém, 2014.

SILVA, W. B. da. A Emergência da atenção farmacêutica: um olhar epistemológico e contribuições para o seu ensino. 2009. Tese (Doutorado em Educação Científica e Tecnológica) - Universidade Federal de Santa Catarina, Florianópolis, 2009.

SKALINSKI, L. M. Epidemiologia e epidemiologia crítica: considerações sobre diferentes estilos de pensamento. 2008. Dissertação (Mestrado em Saúde Coletiva) - Universidade Federal de Santa Catarina, Florianópolis, 2008. 
SLONGO, I. I. P. A produção acadêmica em ensino de biologia: um estudo a partir de teses e dissertações. 2004. Tese (Doutorado em Educação) - Universidade Federal de Santa Catarina, Florianópolis, 2004.

SOUZA, B. V. A Sustentabilidade Ambiental no Ensino de Química na Compreensão de Professores do Ensino Médio. 2013. Dissertação (Mestrado em Educação Científica e Tecnológica) - Universidade Federal de Santa Catarina, Florianópolis, 2013.

SOUZA, R. D. de. Circulações de conhecimentos e práticas na formação inicial de professores de ciências: complicações, subsídios e possibilidades. 2015. Dissertação (Mestrado em Ensino de Ciências e Tecnologia) - Universidade Tecnológica Federal do Paraná, Ponta Grossa, 2015.

TAKEHARA, D. Hanseníase tem cura: Análise dos discursos de pacientes e profissionais de saúde a respeito dos materiais educativos impressos sobre hanseníase. 2013. Dissertação (Doutorado em Educação e Saúde na Infância e Adolescência) - Universidade Federal de São Paulo, São Paulo, 2013.

TAVARES, A. C. $\mathbf{O}$ ensino de patologia humana e suas relações históricas com o estilo de pensamento a partir da análise de livros-texto. 2008. Dissertação (Mestrado em Educação) - Universidade de Brasília, Brasília, 2008.

TESSER, C. D. Epistemologia contemporânea e saúde: a luta pela verdade e as práticas terapêuticas. 2004. Tese (Doutorado em Saúde Coletiva) - Universidade Estadual de Campinas, Campinas, 2004.

TOMIO, D. Circulando sentidos pela escrita nas aulas de ciências: com interlocuções entre Fritz Müller, Charles Darwin e um coletivo de estudantes. 2012.Tese (Doutorado em Educação Científica e Tecnológica) - Universidade Federal de Santa Catarina, Florianópolis, 2012.

TRÉZ, T. de A. e. O uso de animais no ensino e na pesquisa acadêmica: estilos de pensamento no fazer e ensinar ciência. 2012. Tese (Doutorado em Educação Científica e Tecnológica) - Universidade Federal de Santa Catarina, Florianópolis, 2012.

UCHÔA, S. A. da C. Os protocolos e a decisão médica: evidências e ou vivências? 2003. Tese (Doutorado em Saúde Coletiva) - Universidade do Estado do Rio de Janeiro, Rio de Janeiro, 2003. 
VENCAO, A. T. Estilo de pensamento dos professores da área de matemática no curso de engenharia elétrica. 2015. Dissertação (Mestrado em Educação) Universidade do Planalto Catarinense, Lages, 2015.

YAMAZAKI, S. C. Tradição do ensino de física em manuais de ensino superior. 2015. Tese (Doutorado em Educação Científica E Tecnológica) - Universidade Federal de Santa Catarina, Florianópolis, 2015.

\section{Recebido: 2017-06-20}

Aprovado: 2017-08-09

DOI: $10.3895 /$ rbect.v11n1.6041

Como citar: LORENZETTI, L.; MUENCHEN, C.; SLONGO, I. I. P. A crescente presença da epistemologia de Ludwik Fleck na pesquisa em educação em ciências no Brasil. Revista Brasileira de Ensino de Ciência e Tecnologia, v. 11, n. 1, 2018. Disponível em: <https://periodicos.utfpr.edu.br/rbect/article/view/6041>. Acesso em: xxx. Correspondência: Leonir Lorenzetti - leonirlorenzetti22@gmail.com Direito autoral: Este artigo está licenciado sob os termos da Licença Creative Commons-Atribuição 4.0 Internacional.

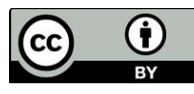

